\title{
CORRECTION OF THE TEMPERATURE EFFECT IN 1020 NM BAND OF SUN-SKY RADIOMETER
}

\author{
Kaitao $\mathrm{Li}^{1}$, Zhengqiang $\mathrm{Li}^{1,}{ }^{1}$, Donghui $\mathrm{Li}^{1}$, Yisong $\mathrm{Xie}^{1}, \mathrm{Hua} \mathrm{Xu}{ }^{1}$ \\ ${ }^{1}$ State Environmental Protection Key Laboratory of Satellite Remote Sensing, Institute of remote sensing and digital earth, Chinese \\ academy of sciences, 100101 Beijing, China - (likt, lizq, lidh, xieys, xuhua)@ radi.ac.cn
}

Commission III, ICWG III/IVb

KEY WORDS: Temperature Correction, 1020 nm Band, Radiometer

\begin{abstract}
:
Aerosol is an important part of the earth-atmosphere system. It can directly and indirectly influence solar radiation and then affect the energy balance of earth-atmosphere system. AERONET, as the largest ground-based observation network, provides multiparameters of aerosol from more than 600 hundred sites using sun-sky radiometer, which contains 9 channels from $340 \mathrm{~nm}$ to 1640 $\mathrm{nm}$. Among which, $1020 \mathrm{~nm}$ channel is greatly influenced by the temperature.
\end{abstract}

In this paper, a new correction method of $1020 \mathrm{~nm}$ band is introduced. The new method transfers the temperature correction coefficient of the master radiometer to the comparative one. The filed calibration experiment shown that the temperature correction coefficient obtained by this method is close to the result from the temperature controlled chamber, and the difference is about $2.1 \%$. This new method is easy-to-use, and its accuracy is comparable to the standard one. It is more applicable for large-scale instrument calibration. In principle, this method is applicable to all bands of the sun-sky radiometer.

\section{INTRODUCTION}

Aerosol is an important part of the earth-atmosphere system. It can directly and indirectly influence solar radiation and then affect the energy balance of earth-atmosphere system (Kaufman et al., 2002, 2006). However, due to the large spatial and temporal distribution of aerosols, the lack of well knowledge of aerosol parameters has led to the aerosols being one of the most uncertain factors in climate assessment (IPCC, 2007).

Ground-based aerosol observations are the relative most accurate and easy-to-operational method to obtain aerosol characteristics, and the acquired aerosol parameters are comprehensive, including aerosol optical, physical, and even chemical property parameters (Li et al., 2017). As the world's largest ground-based aerosol observation network, AERONET (Holben et al., 1998), provides multi-parameters of aerosol from more than 600 sites all over the world using Cimel sun-sky radiometer (CE318), which contains 9 bands from $340 \mathrm{~nm}$ to $1640 \mathrm{~nm}$, of which $936 \mathrm{~nm}$ band for the water vapor detection, and the remaining 8 bands are all for the aerosol observations. In these 8 bands, the $1020 \mathrm{~nm}$ channel is sensitive to the ambient temperature due to the temperature dependency of the detector (Eck et al.,2001) and the filter (Holben, 2008; Andor, 1989). Plastic polarizing filters, used in the polarized radiometers (CE318-DP), can also introduce some temperature dependency (Holben et al., 1998; Berjón et al., 2013). The temperature can affect the observed signal in this band up to about $3.00 \mathrm{E}-3 /{ }^{\circ} \mathrm{C}$ according to the detector manufacture (Fig. 1). In the polar region, the temperature effect causes the difference of aerosol optical depth up to or even more than $50 \%$ (Fig. 2, Li et al., 2013). At the same time, the AERONET inversion algorithm takes this band as one of the four standard bands for aerosol characteristics inversion. The inversion results will be a larger deviation when the temperature effect of this band is not well corrected. Therefore, it is necessary to perform temperature effect correction on this band.

Calibration is the basis for ensuring the correct observation of the instrument. At present, the calibration of direct sun channels adopts the Langley calibration method and the inter-comparison calibration (Holben et al., 1998). The radiance calibration uses an integrating sphere as light source or vicarious calibration method introduced by $\mathrm{Li}$ et al. (2008, 2013). For $1020 \mathrm{~nm}$ channel, the standard coefficient used in AERONET is approximately $2.50 \mathrm{E}-3 /{ }^{\circ} \mathrm{C}$ (Holben et al., 1998; Eck et al., 2001). However, the temperature sensitivity for each photometer is not the same, with an uncertainty in the temperature coefficients about $5.0 \mathrm{E}-4 /{ }^{\circ} \mathrm{C}$ (Holben et al., 1998). In order to get a better data quality, AERONET has begun to thermally characterize the response of each photometer by means of laboratory measurements in a temperature controlled chamber (Holben et al., 2008). For those who do not have temperature controlled chamber, the temperature correction is more difficult to complete. Berjón et al. (2013) established a temperature correction method of sun-sky photometers by field comparison with a reference instrument. The temperature correction coefficients for different bands were obtained by fitting the relationship between the observed signal ratio of two instruments and the temperature.

In this paper, a new alterative correction method of $1020 \mathrm{~nm}$ band is introduced. The new method transfers the temperature correction coefficient of the master radiometer to the comparative one by comparing the extinction optical depth. The filed calibration experiment shown that the temperature correction coefficient obtained by this method is close to the result from the temperature controlled chamber, and the difference is about $2.1 \%$. This new method is easy-to-use, and its accuracy is comparable to the standard one. It is more applicable for network radiometers calibration. 


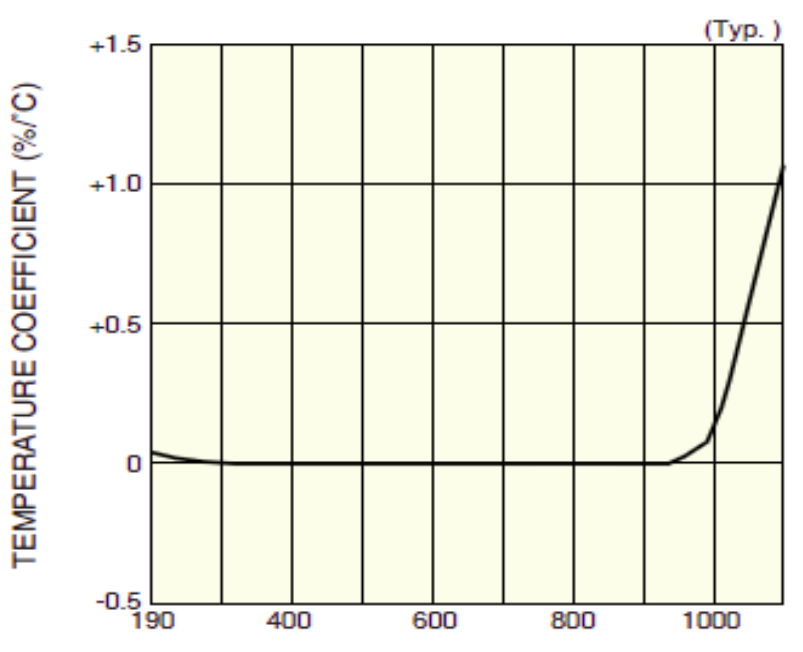

WAVELENGTH $(\mathrm{nm})$

Fig. 1 Temperature effect of S1336 series silicon photodiode from the manufacture (http://www.hamamatsu.com.cn).

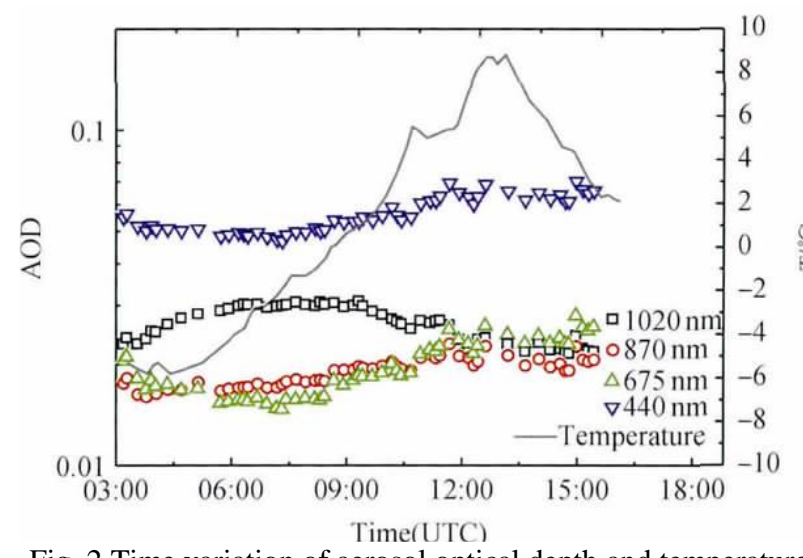

Fig. 2 Time variation of aerosol optical depth and temperature at different wavelength at Vechernaya_Hill site in the Antarctic (extract the figure 1 from $\mathrm{Li}$ et al., 2013)

\section{METHODOLOGY}

AERONET uses a quadratic curve fitting formula to perform temperature correction on the $1020 \mathrm{~nm}$ band, while other bands use a straight-line fitting formula (Holben, 2010). In this paper, for the sake of simplification, a linear fitting formula is applied to the $1020 \mathrm{~nm}$ band according to Li et al. (2013),

$$
V^{\prime}=\frac{V}{1+C(\mathrm{~T}-25)}
$$

where $V$ is instrument observation signal at actual temperature, $V^{\prime}$ is the instrument signal corrected to $25^{\circ} \mathrm{C}$, and $C$ is temperature correction coefficient.

According to the Beer-Lambert-Bouguer law, the relationship between the measured signal value $V$ and extinction optical depth at a specific wavelength is (Biggar et al., 1990),

$$
V=V_{0} \exp (-\mathrm{m} \tau)
$$

where $V_{0}$ is the direct-sun calibration coefficient, $m$ is the airmass, and $\tau$ is the extinction optical depth, including the scattering and absorption optical thickness of atmospheric molecules and aerosol particles.

In conjunction with formulas (1) and (2), the total optical thickness is expressed when the temperature correction of the observed signal is not considered as:

$$
\tau=\frac{1}{m} \cdot \ln \frac{V_{0}}{V}
$$

When considering the temperature effect correction of the observed signal, the total optical thickness after correction is $\tau$ ':

$$
\tau^{\prime}=\frac{1}{m} \cdot \ln \frac{V_{0}}{V^{\prime}}=\frac{1}{m} \cdot \ln \frac{V_{0}}{V}+\frac{1}{m} \cdot \ln (1+C(\mathrm{~T}-25))
$$

Subtraction of formulas (4) and (3), one can get,

$$
\Delta \tau=\frac{1}{m} \cdot \ln (1+C(\mathrm{~T}-25))
$$

In the above formula, $m$ can be accurately obtained through an empirical formula, then the optical thickness difference $(\exp (m \Delta \tau)-1)$ and the temperature (T-25) show a linear relationship, and the temperature correction coefficient of the $1020 \mathrm{~nm}$ band can be obtained through linear fitting. At the same time, to obtain a better fitting result, the temperature at the time of observation should be quite different from $25^{\circ} \mathrm{C}$, and the daily temperature change should also be large.

In the actual observation, one can use a standard radiometer and a slave instrument to be calibrated for simultaneous observation, and it is considered that the extinction optical depth of the standard radiometer is the result of the temperature effect correction.

\section{EXPERIMENT AND RESULTS}

Two sun-sky radiometers \#982 and \#814 from the SONET observation network were used in this experiment. Both radiometers were well temperature-corrected by the temperature controlled chamber at the PHOTONS and all had standard temperature correction coefficients. The comparison calibration experiment was carried out in the mountainous areas in the west of Beijing. The time was August 2016, and the daily temperature change was $18 \sim 31^{\circ} \mathrm{C}$. The temperature difference was relatively large and satisfies the fitting requirement of formula (5).

In the experiment, \#814 was used as the standard instrument, and \#982 was the instrument to be calibrated. The linear change of optical thickness difference and temperature difference between the two instruments was shown in Fig. 3. From the figure, the two parameters have a good linearity, the correlation coefficient up to 0.89 (as shown in Fig. 4). Then these two parameters were linear fitted. The results are shown in Fig. 4. The obtained temperature correction coefficient was 0.00348 , and the laboratory temperature control box obtained a result of 0.00355 . The difference between the two is about $2.1 \%$, as shown in Table 1. 


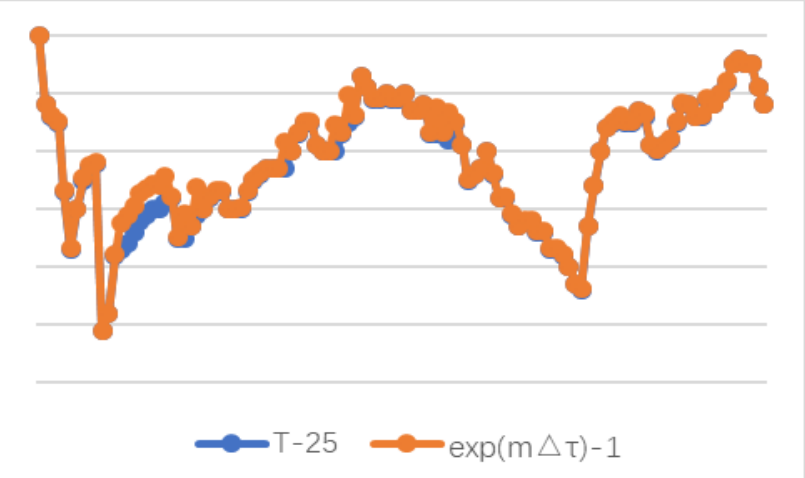

Fig. 3 Variation Trend of Optical Thickness Difference and Temperature Difference. As can be seen from the figure, the two have a good linear correlation.

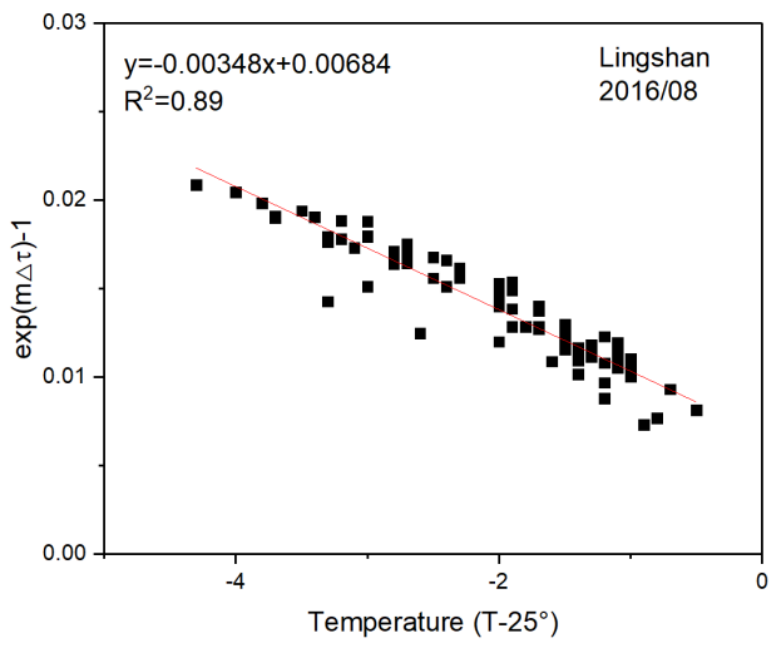

Fig. 4 Fitting results of temperature correction coefficient. One can see that the correlation of the two curves is 0.89 , and the fitting temperature correction coefficient is 0.00348 .

\begin{tabular}{|c|c|c|c|}
\hline Instrument & Fitted Coeff. & Coeff. In Lab & Diff. \% \\
\hline$\# 0982$ & 0.00355 & 0.00348 & 2.1 \\
\hline
\end{tabular}

Table 1. Comparison of calibration results. The difference between two results is about $2.1 \%$.

\section{CONCLUSIONS}

In this paper, a new correction method of $1020 \mathrm{~nm}$ band is introduced. The new method transfers the temperature correction coefficient of the master radiometer to the comparative one by comparing the extinction optical depth. The principle of this method is that, according to the Beer's law and temperature correction formula, two radiometers are used in this method, one is the radiometer to be calibrated, and the other is a standard instrument. Between them, the correction of temperature effect of the standard instrument is calibrated by the standard temperature controlled chamber at PHOTONS. It is considered that the extinction optical depth calculated from this standard radiometer is the correct result, and the differences between the standard extinction optical depth and the extinction optical depth calculated from radiometer to be calculated without any temperature correction are calculated. Then the extinction optical depth differences are fitted to the observation temperatures to obtain the temperature correction coefficient for this band.
In this paper, a filed calibration experiment was taken in Beijing in August 2017 to illustrate this new method, two radiometers, No. \#982 and \#814 were used in this experiment, and the \#814 radiometer is considered as a standard one. Results shown that the temperature correction coefficient obtained by this method is equivalent to that the result from the temperature controlled chamber, and the difference is about $1.2 \%$.

This new method is easy-to-use, and its accuracy is comparable to the standard ones. It is more applicable for large-scale instrument calibration. However, this new method requires large temperature differences during the observation period and is generally selected to be more reasonable in cold season. In principle, this method is applicable to all the bands of the sunsky radiometer, but the temperature in the rest of the bands is less affected.

\section{ACKNOWLEDGEMENTS}

This work is supported by the National Natural Science Foundation of China (NSFC) (41701405) and the National Key R\&D Program of China (2016YFE0201400). The authors would like to thank the PHOTONS and SONET staffs for calibrating and maintaining the two radiometers used in this paper.

\section{REFERENCES}

Andor, G. (1989). Temperature dependence of high accuracy photometer heads. Applied Optics, 28(22), 4733_4731-4734. doi:10.1364/AO.28.4733_1

Berjón, A., Torres, B., Toledano, C., Podvin, T., Blarel, L., Prats, N., Goloub, P., and Cachorro, V. E. (2013). Characterization of temperature sensitivity of sun photometers by field comparison with a reference instrument. Journal of Aerosol Science, 59(0), 1-5. doi:10.1016/j.jaerosci.2013.01.005

Eck, T. F., Holben, B. N., Dubovik, O., Smirnov, A., Slutsker, I., \& Lobert, J. M., et al. (2012). Column- integrated aerosol optical properties over the maldives during the northeast monsoon for 1998- 2000. Journal of Geophysical Research Atmospheres, 106(D22), 28555-28566.

Holben, B. N. (2008). <http://aeronet.gsfc.nasa.gov/new_web/AERONET_Annual_Review08_final.pdf $>$. AERONET Annual review.

Holben, B. N. (2010). <http://aeronet.gsfc.nasa.gov/new_web/Documents/AERONET_Update_4-10.pdf $>$. AERONET update.

Holben, B. N., Eck, T. F., Slutsker, I., Tanré, D., Buis, J. P., Setzer, A., Vermote, E., Reagan, J. A., Kaufman, Y. J., Nakajima, T., Lavenu, F., Jankowiak, I., and Smirnov, A. (1998). AERONET - A Federated Instrument Network and Data Archive for Aerosol Characterization. Remote Sensing of Environment, 66(1), 1-16. doi:10.1016/s0034-4257(98)00031-5

Kaufman, Y. J., and Koren, I. (2006). Smoke and pollution aerosol effect on cloud cover. Science, 313(5787), 655-658. doi:10.1126/science. 1126232

Kaufman, Y. J., Tanre, D., and Boucher, O. (2002). A satellite view of aerosols in the climate system. Nature, 419(6903), 215223. doi:10.1038/nature01091 
Li, D., Li, Z., Bian, L., Li, K., Li, B., Gu, X., and Podvin, T. (2013). Analysis of aerosol properties using ground-based sunsky radiometer in polar region. Journal of Remote Sensing, 17(3), 553.

Li, Z. Q., Xu, H., Li, K. T., Li, D. H., Xie, Y. S., Li, L., . . Bu, D. (2017). Comprehensive study of optical, physical, chemical and radiative properties of total columnar atmospheric aerosols over China: An overview of Sun-sky radiometer Observation NETwork (SONET) measurements. Bulletin of the American Meteorological Society, 0(0), null. doi:10.1175/bams-d-170133.1

Li, Z., Blarel, L., Podvin, T., Goloub, P., Buis, J. P., and Morel, J. P. (2008). Transferring the calibration of direct solar irradiance to diffuse-sky radiance measurements for CIMEL Sun-sky radiometers. Applied Optics, 47(10), 1368-1377. doi:10.1364/AO.47.001368

Li, Z., Goloub, P., Blarel, L., Yang, B., Li, K., Podvin, T., Li, D., Xie, Y., Chen, X., Gu, X., Zheng, X., Li, J., and Catalfamo, M. (2013). Method to intercalibrate sunphotometer constants using an integrating sphere as a light source in the laboratory. Applied Optics, 52(11), 2226-2234. doi:10.1364/AO.52.002226

Ramanathan, V., Crutzen, P. J., Kiehl, J. T., and Rosenfeld, D. (2001). Aerosols, climate, and the hydrological cycle. Science, 294(5549), 2119-2124. doi:10.1126/science.1064034

Solomon, S., Qin, D., Manning, M., Marquis, M., Averyt, K., Tignor, M. M. B., Miller, L., and Chen, Z. (2007). IPCC, 2007: Climate Change 2007: The Physical Science Basis. Contribution of Working Group I to the Fourth Assessment Report of the Intergovernmental Panel on Climate Change. Cambridge, United Kindom and New York, NY, USA: Cambridge University Press. 